\title{
Pró-equidade de gênero: incorporando políticas de ação afirmativa no mundo do trabalho
}

Elisabeth Lisbôa Pinto, Hermes Andrade Júnior e Rodolfo Pinto da Luะ

\section{Introdução}

O movimento feminista e de mulheres foi o meio inicial de que se utilizaram as mulheres em busca de verem respeitados seus direitos. A mulher procurava exercer de forma plena sua cidadania, conquistando direitos que se tornaram referência para a sua luta e para a sociedade em geral, como a fundamental manifestação por meio do voto.

A sua inserção no mercado de trabalho se caracteriza por muitas lutas, conquistando espaços hoje consolidados, sem que se perceba a possibilidade de retorno (ABRAmo, 2007). Essa participação teve início na década de 1950, acentuando-se nos anos 1970, com a intenção de aumentar a renda familiar, em consequência da crise econômica, que trazia alto índice de desemprego.

O processo de inclusão no mercado trabalhista contribuiu para tornar mais visível a divisão do trabalho, constatada por meio dos critérios de acesso, remuneração e oportunidades de ascensão. No contexto de conquistas e reflexões, a mulher compreendeu que uma das formas de reduzir as desigualdades nesse 
campo é o aumento do nível de escolaridade. Contudo, segundo afirma Abramo (2007), mesmo com o aumento do nível de escolaridade da mulher em relação ao do homem, permanecem as desigualdades.

$\mathrm{Na}$ área pública, as condições de acesso mostram-se a priori superadas, devido à imposição legal de concurso público, a que estão submetidas todas as empresas e instituições. Entretanto, as formas sutis de desigualdade, tacitamente estabelecidas, escapam ao arcabouço legal vigente, expressando-se de forma clara no número reduzido de mulheres que chegam ao topo da pirâmide hierárquica (SEGNini, 1998).

Portanto, a condição da mulher nas relações sociais, no espaço organizacional, tem incentivado a reflexão sobre os diversos motivos que justificam tal realidade. Essa situação inquieta e reforça o interesse em conhecer de maneira detalhada o Programa Pró-equidade de Gênero da Secretaria de Políticas para as Mulheres da Presidência da República (SPM/PR), tendo como referencial teórico o modelo "policy cycle como aprendizado", que é adotado neste trabalho.

Este estudo é apresentado em seis partes: na primeira são demonstrados os procedimentos metodológicos empregados no trabalho de campo; em seguida apresentamse o Programa Pró-equidade de Gênero e a avaliação de suas duas primeiras edições; a terceira parte é constituída de breve contextualização das políticas públicas nos anos 2000; continuando, apresenta-se o "policy cycle como modelo de aprendizagem"; na quinta parte, manifesta-se a compreensão das relações entre o programa e o modelo policy cycle; e no último tópico, expressam-se as considerações finais, a partir das lições apreendidas com a realização da pesquisa.

\section{Procedimentos metodológicos}

O método deve ser apropriado ao tipo de estudo, mas é a natureza do problema que determina sua escolha, uma vez que as investigações voltadas para uma análise qualitativa têm como objetivo situações complexas ou estritamente particulares (RICHARDSON, 2008).

Desse modo, compreende-se que a abordagem qualitativa, como estratégia de estudo exploratório, é a mais adequada, além de gerar estruturas soltas com o objetivo de descobrir futuras tarefas de pesquisa (CoOper e SCHINDler, 2003).

A coleta de dados ocorreu em documentos da SPM e referências bibliográficas dos autores Pedro Luís Barros e Silva e Marcus André Barreto de Melo, no período de fevereiro e março de 2009.

Os dados coletados foram tratados de maneira que pudessem ser estabelecidas relações entre o programa e o referencial teórico.

Assim, pretende-se apresentar o programa e discuti-lo com base no modelo "policy cycle como aprendizado", visando orientar a construção de um modelo de investigação para um projeto de pesquisa futura.

\section{Programa Pró-equidade de Gênero}

As políticas públicas de gênero têm gerado polêmicas, no movimento feminista e de mulheres, em relação ao papel do Estado, pois enquanto aquelas da vertente mais liberal consideram o Estado neutro, as radicais e socialistas consideram-no patriarcal, caracterizando a complexidade desse fenômeno social que envolve diversas nuances (STROMQUIST, 1996). 
No Brasil, entre os anos de 1964 a 1984, vivia-se um período de grandes oscilações no processo democrático. Anos marcados pelo autoritarismo burocrático do governo militar, apoiado nas ideologias de segurança nacional e progresso com ordem. Todo esse período se constituiu de muitas lutas pelo restabelecimento do processo democrático por meio de movimentos cada vez mais organizados; entre eles, o movimento feminista e de mulheres, que trouxe questões entremeadas na teia social, as quais explicitam as desigualdades entre homens e mulheres e entre mulheres brancas e negras (SousA, 2007).

Nesse contexto, as mulheres percebem a redução de espaço para discutir questões nos seus sindicatos. Essa consciência impulsionou avanços significativos na vida sindical, levando à organização dos departamentos de mulheres e fazendo com que a questão fosse incluída na agenda dos sindicatos.

O Departamento Intersindical de Estatística e Estudos Socioeconômicos (Dieese), em 1996, a partir das demandas das mulheres das principais centrais sindicais (CUT, Força Sindical e CGT), desenvolve profundo estudo no qual disponibiliza instrumentos e informações que aprimoram o trabalho sindical nas negociações coletivas entre empregadores e empregados, quando surgem as oportunidades de avançar em ações afirmativas quanto à equidade de gênero.

Somam-se a esse momento movimentos ocorridos em torno de questões sociais, em anos que antecederam a instalação da Assembleia Constituinte. Em 1988, a Constituição Federal, denominada "constituição cidadã", consolida várias conquistas que expressam as lutas das mulheres - salários iguais para serviços iguais; licença-maternidade de 120 dias; licença-paternidade de 5 dias etc. - e aponta como um de seus princípios a promoção da igualdade entre mulheres e homens.

Assim, as lutas dos movimentos de mulheres, o princípio constitucional, a pressão sindical, as mudanças gerais e de valores ocorridas na sociedade são argumentos que pressionaram para inclusão das questões de gênero na agenda governamental (STROMQUist, 1995).

De fato, a incorporação da dimensão de gênero na agenda governamental teve

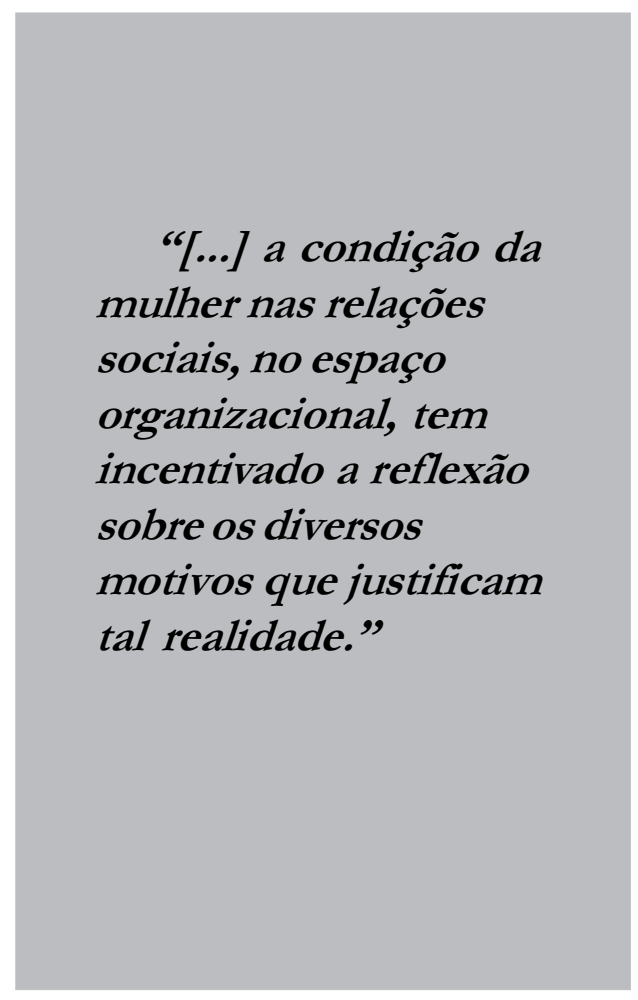

início, em 1985, com a criação do Conselho Nacional de Direitos da Mulher, que desempenhou papel fundamental - por meio do chamado "lobby do batom" no processo de inclusão dos direitos das mulheres na Constituição Federal, inaugurando dentro do governo a elaboração de ações , principalmente na área da saúde, a exemplo do Programa de Ação Integral à 
Saúde da Mulher (PAISM). Também contribuíram a pressão do movimento sindical e a oportunidade surgida com os fóruns internacionais, que tinham em suas pautas o reconhecimento e a luta pela desigualdade de gênero. Como diz Rua (2006), a inclusão desses fenômenos na agenda pode ocorrer em consequência de uma crise, como um surto de dengue; da ação política mobilizadora com poder político, como no movimento pelas Diretas Já; ou ainda pela pressão social.

Aprovada na II Conferência Nacional de Políticas para as Mulheres (CNPM), em agosto de 2007 - que ratificou alguns pontos da I CNPM, de julho de 2004 -, a Política Nacional para as Mulheres, que tem como princípio a equidade de gênero, orientou a política pública para que atendesse à demanda social.

Como desdobramento da política pública (FARAH, 2004), foi criado em 2005 o Programa Pró-equidade de Gênero, instituído pelo Decreto no $5.390 / 2005$, cuja formulação e avaliação estão a cargo da Secretaria Especial de Políticas para as Mulheres (SPM) da Presidência da República. O programa realizou a sua primeira edição no biênio 2005/2006, a segunda em 2007/2008 e a terceira em 2009/2010.

O Pró-equidade de Gênero tem como norteador o princípio constitucional de promover a igualdade entre mulheres e homens. O objetivo geral é contribuir para a eliminação de todas as formas de discriminação no acesso, remuneração, ascensão e permanência no emprego. Os objetivos específicos são conscientizar e sensibilizar dirigentes, empregadores(as) e trabalhadores(as); estimular a prática de gestão que promova a igualdade de oportunidades entre homens e mulheres dentro das organizações; reconhecer publicamente o compromisso das organizações com a equidade de gênero no mundo do trabalho; criar a rede Pró-equidade de Gênero; e construir um banco de boas práticas de gestão que possibilite a troca de experiências de promoção da equidade de gênero no trabalho.

A partir da terceira edição, que começou em 2009, o programa expandiu seu campo de atuação para organizações públicas e privadas, com ou sem fins lucrativos, com perfil de médio e grande porte. Percebe-se que houve um avanço em relação à primeira edição, quando a ação estava focada apenas no setor público.

A coordenação do Pró-equidade de Gênero está a cargo da Secretaria Especial de Políticas para as Mulheres, do Ministério do Planejamento, Orçamento e Gestão (MP), do Ministério Público do Trabalho (MPT), da Organização Internacional do Trabalho (OIT), do Fundo de Desenvolvimento das Nações Unidas para a Mulher (Unifem) e do Conselho Nacional dos Direitos da Mulher (CNDM). Há ainda um comitê formado por integrantes de núcleos de estudos de gênero de universidades públicas, instituído com o objetivo de qualificar mais o processo de assessoramento, monitoramento e implementação dos planos de ação definidos pelas empresas e instituições participantes.

A adesão ao programa se dá de forma voluntária, com preenchimento de "ficha perfil”, que permite diagnóstico básico para a construção de plano de ação a ser implementado no âmbito interno da empresa/instituição, estruturado em dois grandes eixos: gestão de pessoas e cultura organizacional. Esse plano é pactuado entre a organização e o Comitê Pró-equidade de Gênero.

A criação do Comitê Pró-equidade de Gênero, no âmbito das organizações participantes, constitui-se um dos aspectos 
considerados importantes, uma vez que é o responsável pela proposição e desenvolvimento das iniciativas que constituirão o plano de ações, e cotidianamente poderão vir a mudar as relações de gênero no ambiente do trabalho.

A implementação do plano de ações se desenvolve em três etapas:

- adesão voluntária - implica o preenchimento do termo de adesão, que deve ser firmado pelo primeiro gestor. Significa o compromisso de permanência no programa; caso contrário, a adesão é desconsiderada;

- levantamento de informações sobre o perfil da organização e seu quadro de pessoal - é realizado por meio do preenchimento da ficha perfil;

- diagnóstico da organização - subsidia a formulação do plano de ação com o objetivo de promover a equidade de gênero. Depois de pactuado com o Comitê Próequidade de Gênero, deve ser entregue em um prazo de até 30 dias, após a ficha perfil.

O monitoramento e a avaliação dos compromissos dispostos no plano de ações são feitos pelo Comitê Pró-equidade de Gênero, levando em conta critérios firmados no momento da pactuação com a organização.

\section{O Selo Pró-equidade de Gênero}

Durante o período de aplicação do plano de ações, a organização é acompanhada pela SPM, que também oferece apoio técnico. O cumprimento dos objetivos e metas de cada organização lhe dá condições de receber o Selo Pró-equidade de Gênero.

O selo é um atributo que distingue a empresa/instituição comprometida com o combate à discriminação e com a promoção da igualdade entre homens e mulheres no mundo do trabalho (SPM, 2008). A Secretaria Especial de Políticas para as Mulheres, o Unifem e a OIT têm o compromisso de divulgar nacional e internacionalmente as organizações que obtiveram o selo, demonstrando o reconhecimento pelo trabalho em busca de equidade das relações de gênero.

Em sua 1a edição, dirigida apenas às empresas/instituições públicas, das 16 organizações participantes, 11 receberam o Selo Pró-equidade de Gênero (Quadro 1).

Já na segunda edição (2007/2008), o programa registrou crescimento da participação e também do número de organizações agraciadas com o Selo Pró-equidade de Gênero, que passou de 11 para 23. Das organizações que haviam recebido o selo na primeira edição, somente a Companhia Energética de Alagoas não estava entre as novamente contempladas.

Em 2007/2008, as instituições certificadas com o selo de reconhecimento pelo cumprimento das ações pactuadas na segunda edição do Programa Pró-equidade de Gênero foram: Banco do Brasil (BB); Banco do Nordeste do Brasil (BNB); Banco Nacional de Desenvolvimento Econômico e Social (BNDES); Caixa Econômica Federal (CEF); Centro de Pesquisa de Energia Elétrica (Cepel); Centrais Elétricas do Norte do Brasil (Eletronorte); Centrais Elétricas S.A. (Eletrosul); Centrais Elétricas Brasileiras S.A. (Eletrobrás); Companhia de Eletricidade do Amapá (CEA); Companhia de Geração Térmica de Energia Elétrica; Companhia Hidroelétrica do São Francisco (Chesf); Eletrobrás Termonuclear S.A. (Eletronuclear); Empresa Brasileira de Pesquisa Agropecuária (Embrapa); Empresa Brasileira de Infraestrutura Aeroportuária (Infraero); Furnas Centrais Elétricas S.A.; Grupo Hospital N. Sra. da Conceição; Itaipu Binacional; Manaus Energia; Petróleo Brasileiro S.A. (Petrobrás); Petros - Fundação de Seguridade Social; Prefeitura Municipal de Quixadá; Serviço 


\section{Quadro 1: Organizações públicas que receberam o Selo Pró-equidade de Gênero, na $1^{a}$ edição - biênio 2005/2006}

\begin{tabular}{|c|c|}
\hline $\begin{array}{l}\text { Empresas/instituições } \\
\text { públicas }\end{array}$ & Principais ações \\
\hline $\begin{array}{l}\text { Caixa Econômica Federal } \\
\text { (CEF) }\end{array}$ & $\begin{array}{l}\text { Aumento do número de mulheres e de negros em cargos gerenciais } \mathrm{c} \\
\text { reconhecimento das unidades regionais com melhores indicadores de gênero. }\end{array}$ \\
\hline $\begin{array}{l}\text { Centro de Pesquisa de Energia } \\
\text { Elétrica (Cepel) }\end{array}$ & Obtenção de dados dos funcionários desagregados por sexo, raça/cor e escolaridade. \\
\hline $\begin{array}{l}\text { Companhia Energética de } \\
\text { Alagoas }\end{array}$ & $\begin{array}{l}\text { Recorte de gênero nos cursos e treinamentos e alteração do cadastro de registro do } \\
\text { sistema de informação dos funcionários, com a inclusão de dados de sexo, raça, etnia e } \\
\text { escolaridade. }\end{array}$ \\
\hline $\begin{array}{l}\text { Companhia de Geração } \\
\text { Térmica de Energia Elétrica }\end{array}$ & $\begin{array}{l}\text { Disseminação dos dados apontados no diagnóstico da desigualdade de gênero e raça e } \\
\text { divulgação do programa por meio de logomarca e slogan. }\end{array}$ \\
\hline $\begin{array}{l}\text { Centrais Elétricas do Norte do } \\
\text { Brasil (Eletronorte) }\end{array}$ & $\begin{array}{l}\text { Inclusão do programa no planejamento estratégico da empresa, assegurando que a gestão } \\
\text { de pessoas esteja alinhada com os desafios empresariais; institucionalização do plano de } \\
\text { ação e exigência de definição de indicadores para cinco anos. }\end{array}$ \\
\hline $\begin{array}{l}\text { Eletrobrás Termonuclear S.A. } \\
\text { (Eletronuclear) }\end{array}$ & $\begin{array}{l}\text { Realização de pesquisa sobre a cor/etnia do corpo funcional; atualização do cadastro; e } \\
\text { introdução de recorte de gênero no Código de Ética e no Código de Conduta. }\end{array}$ \\
\hline $\begin{array}{l}\text { Centrais Elétricas S.A. } \\
\text { (Eletrosul) }\end{array}$ & $\begin{array}{l}\text { Realização de ações externas de apoio à igualdade de gênero e à defesa dos direitos das } \\
\text { mulheres; e produção do vídeo Basta, para disseminar, refletir e criar debates sobre } \\
\text { gênero. }\end{array}$ \\
\hline $\begin{array}{l}\text { Centrais Elétricas Brasileiras } \\
\text { S.A. (Eletrobrás) }\end{array}$ & $\begin{array}{l}\text { Criação do Canal de Gênero via internet, tendo como parceira a Ouvidoria Geral, com o } \\
\text { objetivo de disseminar as questôes de gênero. }\end{array}$ \\
\hline Furnas Centrais Elétricas S.A. & $\begin{array}{l}\text { Alteração da redação das normas de funcionamento e dos editais de concurso, para que } \\
\text { seja respeitada a diversidade e garantida a igualdade, utilizando denominações } \\
\text { profissionais no feminino e no masculino; criação da marca "Selo Grupo Género" para } \\
\text { divulgar o compromisso da empresa com a equidade de gènero. Esse selo passou a } \\
\text { constar no material impresso da empresa de circulação interna e externa. }\end{array}$ \\
\hline Itaipu Binacional & $\begin{array}{l}\text { Institucionalização do programa até } 2011 \text { : inserção no planejamento estratégico; produção } \\
\text { de material didático-pedagógico para formação; mobilização e institucionalização das } \\
\text { práticas de equidade; e atualização do perfil social com a inclusão de sexo e raça/etnia. }\end{array}$ \\
\hline $\begin{array}{l}\text { Petróleo Brasileiro S.A. } \\
\text { (Petrobrás) }\end{array}$ & $\begin{array}{l}\text { Realização de pesquisa de responsabilidade social e gênero, para consolidar e interpretar } \\
\text { os indicadores de gênero, constantes nos institutos Balanço Social, Ethos e no İndice } \\
\text { Dow Jones de Sustentability; proposição de Agenda de Gênero para o Sistema Petrobrás; } \\
\text { e nomeação da primeira mulher para o comando de uma unidade industrial. }\end{array}$ \\
\hline
\end{tabular}

Federal de Processamento de Dados (Serpro); e Secretaria de Estado de Trabalho, Renda e Esporte (Setre/Bahia).

Percebe-se que o Programa Próequidade expressa outra concepção na implementação de um programa público, contudo reforça a importância de se conhecer mais profundamente, em especial, a avaliação.

\section{Breve contextualização das políticas públicas nos anos 2000}

As políticas públicas com várias linhas conceituais foram diretamente atingidas pelas profundas mudanças concebidas no setor público, a partir da exigência de ajustes nos gastos, em consequência da crise econômica que afetou especialmente o emprego. Esse cenário se agrava com a crise fiscal, que leva os Estados nacionais a um processo de contenção de gastos e a repensarem o seu tamanho. Essas circunstâncias tornam premente a intervenção governamental para atender as pessoas mais necessitadas (Costa; Castanhar, 2003).

Desse modo, a reforma do setor público está voltada para dois pressupostos básicos: o primeiro diz respeito à contenção de gastos e ao aumento da produtividade com eficiência; o segundo trata da revisão da estrutura do Estado, com redução da participação nas suas decisões. Essas mudanças fizeram com que 
as políticas mudassem um pouco a direção do foco, de forma que os programas, ao serem formulados, tivessem muito claro o processo de reforma do setor público (FARIA, 2005).

Esse cenário foi determinante para o estabelecimento de políticas públicas que eram condicionadas ao cumprimento do ajuste fiscal e da redução da participação do Estado nas decisões, o que passou a ser premissa na formulação, implementação e avaliação de políticas públicas (SouzA, 2007). Isso exige pensar políticas num contexto em que as limitações são evidentes, sem perder o direcionamento, mas superando o pressuposto de que a formulação e a implementação de políticas públicas devam seguir exclusivamente processos racionais e lineares dissociados dos processos políticos (SouzA, 2003), para que os resultados expressem a menor relação custo/benefício no cumprimento dos objetivos e metas, nos impactos, na sustentabilidade, na satisfação do beneficiário e na equidade - grau em que os benefícios estão sendo distribuídos de maneira justa (UniceF, 1990; apud Costa; CAstanhar, 2003).

Assim, as diversas abordagens e o ambiente contribuíram para a decisão sobre as políticas públicas, o que estimula a procura de modelo que expresse uma maior e melhor compreensão da formulação, da implementação e da avaliação de programas, que são o desdobramento das políticas públicas e também são alternativas conceituais aos modelos racional e linear (FARAH, 2004).

\section{Policy Cycle como modelo de aprendizado}

Utiliza-se como referencial teórico deste trabalho o modelo "policy cycle como aprendizado", de Pedro Luís Barros Silva e Marcus André Barreto de Melo.

Apresentado na reunião do Centro Latino-americano de Desenvolvimento (Clad), em 2000, realizada na República Dominicana, durante o painel "Estado Democrático e Governança no Século XXI: reformando a reforma". O modelo foi publicado pelo Caderno do Núcleo de Estudos em Políticas Públicas da

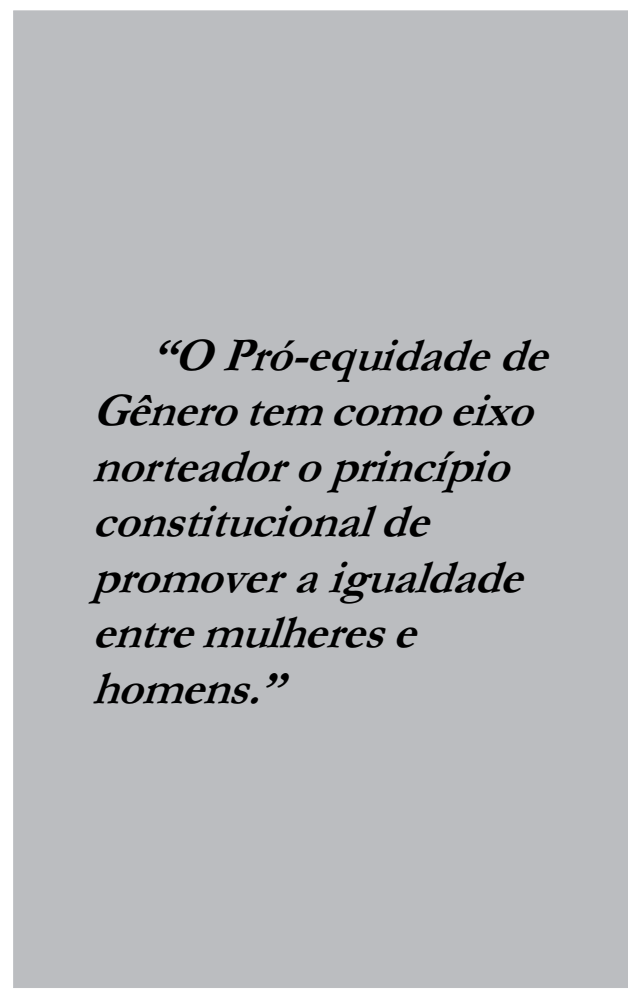

Universidade Estadual de Campinas (NEPP/Unicamp) em 2000.

Os autores consideram como a base de políticas públicas o tripé "formulação, implementação e avaliação". Contudo, reforçam a necessidade de dar atenção à implantação das políticas no complexo contexto institucional e organizacional brasileiro, devido às particularidades que permeiam as diferenças funcionais e as 
questões de coordenação e cooperação dentro da área governamental.

Acreditam também na implementação de políticas públicas como um aspecto decisivo, em que os acertos e desacertos refletem diretamente o sucesso dos governos em busca de atingir os objetivos estabelecidos.

Assim, os autores discutem um modelo alternativo às abordagens clássica (top down), centrada nos mecanismos de controle sobre os agentes implementadores e que não considera os efeitos retroalimentadores; e de processo linear (bottom up), que, embora seja um avanço em relação à abordagem clássica, possui premissas equivocadas, ao priorizar excessivamente a formulação como atividade sem problemas e ao considerar que toda política pública é construída em bases de um modelo causal.

Para Silva e Melo, os formuladores de políticas públicas atuam em ambientes instáveis, com incertezas que dificultam as ações. Os problemas podem ser de ordem cognitiva dos agentes, diante da complexidade dos fenômenos sociais, da dificuldade em manter sob controle algumas situações, o que os limita nas previsões de contingências que podem afetar o policy environment (ambiente de política pública). Por atuarem num espaço de cultura burocrática, mostram-se como barreiras às práticas inovadoras e criativas e de um modo geral veem os programas como experimentações sociais e não como algo ideal.

A implementação do modelo policy cycle é vista como processo autônomo, em que decisões relevantes são tomadas para o sucesso da política. Trata-se de processo que também orienta a formulação de novas políticas. Silva e Melo (2000) continuam afirmando que nessa fase, em que há muitos interesses em jogo, os atores fazem negociações, barganhas e trocas. Contudo, tais ações são manifestadas dentro de princípios organizacionais.

Sendo assim, a avaliação não é apenas uma correção de rota, mas uma etapa de aprendizado na implementação, rompendo com a divisão de trabalho intelectual e manual.

O policy cycle (ciclo de política pública) é ressaltado como campo estratégico no qual há relativa indistinção entre os implementadores e os formuladores, e também entre a população alvo de um programa e os stakeholders (grupos envolvidos nas políticas públicas e nelas interessados segundo conceituação dos autores), conforme apresentado na Figura 1. Portanto, no reconhecimento da etapa de implementação como jogo político, é essencial compreender o papel dos agentes envolvidos pelas políticas e nelas interessados. Nas políticas públicas redistributivas, como os programas da área social, os atores devem ser identificados para que não ocorram apenas adesões oportunistas.

Silva e Melo destacam ainda a importância dos mecanismos de coordenação interinstitucional para implementação de políticas públicas em ambientes democráticos, onde diferentes atores são implementadores. Isso reafirma a tese de "policy cycle como aprendizado", em virtude de torná-la mais consistente e persuasiva, em que o policy cycle é representado pelas redes complexas de atores que sustentam a política e pelos pontos de elevada criticidade, no que se refere à coordenação e aos recursos institucionais. Asseguram a importância dessa coordenação, tendo em vista a diversidade dos atores envolvidos que levam a situações tensas, gerando momentos de crise, cuja superação representa a ocasião de aprendizagem dentro da dinâmica do programa. 


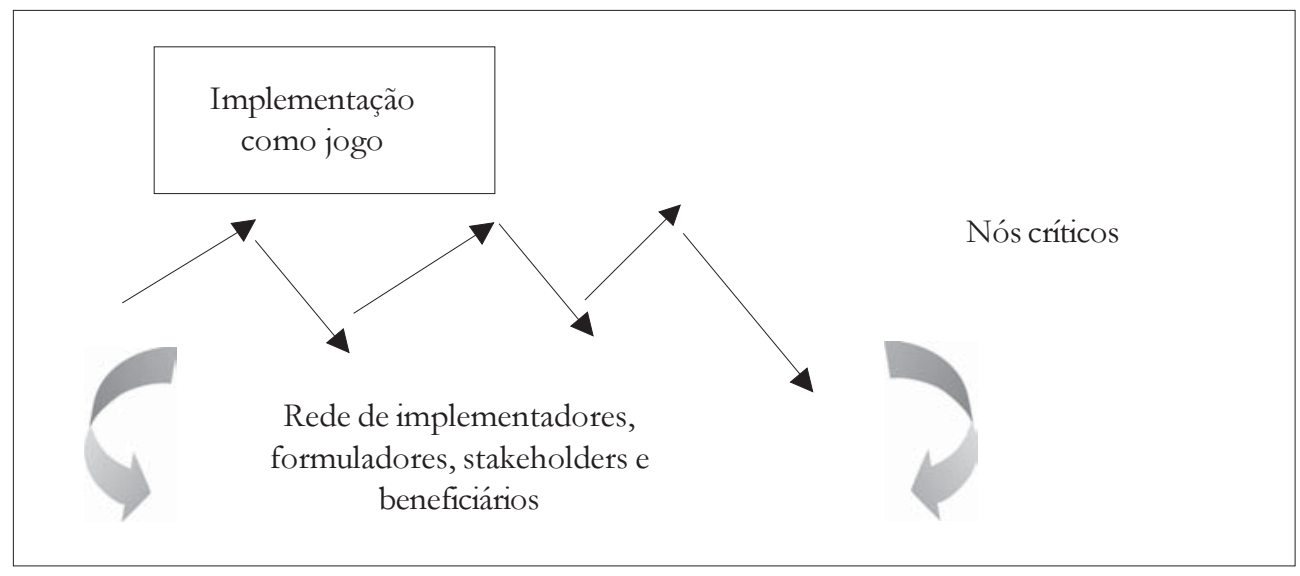

Fonte: Silva e Melo (2000)

Figura 1: O policy cycle como aprendizado

Por fim, essa visão de política pública enquanto aprendizado, articulada a uma rede de agentes, fortalece os mecanismos de implementação de políticas em contextos organizacionais.

\section{O programa Pró-equidade de Gênero e o modelo "policy cycle como aprendizado"}

Presume-se que o Programa Pró-equidade de Gênero tem a sua formulação, implementação e avaliação sustentadas teoricamente no modelo de "policy cycle como aprendizado" proposto por Silva e Melo (2000), uma vez que se caracteriza por tratar de tema revestido pela complexidade, de curso limitado pela sua formatação, e por constituir-se de ações incrementais.

O programa tem a sua formulação elaborada pela Secretaria Especial de Políticas para as Mulheres, enquanto a implementação está vinculada à adesão voluntária das organizações a partir do diagnóstico e elaboração do plano de ação. Tal diagnóstico caracteriza-se, principalmente, pela implementação autônoma, buscando respeitar as especificidades e a diversidade daquela cultura, em que o ambiente organizacional se constitui de incertezas e instabilidades para os diversos processos.

Observa-se outro ponto de compatibilidade com a concepção dos autores, no que se refere às ações estrategicamente selecionadas para pôr em prática as decisões políticas, em geral de ações afirmativas (RUA, 2006). No entanto, constata-se que o programa é de adesão voluntária, o que pressupõe maior complexidade no processo de coordenação pelo estabelecimento de equilíbrio na diversidade de atores e ambientes.

Tal desenho permite ao implementador maior autonomia, na medida em que as empresas são livres para contratar a busca do selo do Pró-equidade, criando ambiente de participação, o que resulta em cumprimento da meta. Como discutido no "modelo policy cycle como aprendizado", supõe-se que essa autonomia dialogue diretamente com o cumprimento e a recriação de metas. Perspectiva importante 
quando se trabalha equidade de gênero, uma vez que essa dimensão não se esgota em uma atividade, um plano ou um programa.

\section{Considerações finais}

Mesmo sendo de adesão voluntária, o Programa Pró-equidade de Gênero oferece forte apelo social na medida em que a organização contemplada com o Selo Pró-equidade de Gênero tem o nome divulgado nacionalmente e internacionalmente pelas instituições coordenadoras do programa (SPM, Unifem e OIT), significando rápida repercussão das ações em um mundo globalizado. Além disso, o selo pode ser utilizado em todos os documentos, correspondências e materiais publicitários da organização.

Diante dos resultados apresentados na primeira e na segunda edição do Programa Pró-equidade de Gênero, pela quantidade de outorgas do selo em relação ao total de participantes, infere-se que os planos de ação das organizações foram eficientes e eficazes. Não fica claro, no entanto, qual o seu impacto, ou seja, até que ponto as ações implementadas foram efetivas. Faz-se necessário, então, aprofundar a investigação com uma observação mais detalhada das mudanças ocorridas entre os funcionários e as comunidades vizinhas das instituições.

(Artigo recebido em julho de 2009. Versão final em dezembro de 2009.)

\section{Referências bibliográficas}

ABrAmo, Laís. Inserção das mulheres no mercado de trabalho na América Latina: uma força de trabalho secundária? In: Hirata, H. e Segnini, L. (Org.) Organização, Trabalho e Gênero. São Paulo: Senac, 2007.

Costa, Frederico; Castanhar, José Cezar. Avaliação de programas públicos: desafios conceituais e metodológicos. Revista de Administração Pública, Rio de Janeiro, 37(5), p.969-92, set./out. 2003.

FArah, M.F. Gênero e políticas públicas. Estudos Feministas, Florianópolis, 12(1), p. 360, jan./abr. 2004.

FARIA, Carlos Aurélio. A política da avaliação de políticas públicas. Revista Brasileira de Ciências Sociais, São Paulo, v. 20, n. 59, p.97-109, out. 2005.

RuA, Maria das Graças. Análise de políticas públicas: conceitos básicos. In: RuA, M. G. O Estudo da política. Brasília: Paralelo 15, 2003.

Sabatier, P. Top down and bottom up approaches to implementation research. Journal of Public Policy, n⿳⼈ 6, 1986.

Secretaria Especial de Políticas para Mulheres (SPM/PR). Programa Pró-equidade de Gênero: oportunidades iguais respeito às diferenças. 2ª ed. Brasília, 2008.

Plano Nacional de Políticas para as Mulheres. Disponível em: http://www.presidencia.gov.br/estrutura_presidencia/sepm/.arquivos integra_ publ_diretrizes_cnpm/. Acesso em: 18 de maio de 2009. 
SEGnini, Liliana. Relações de gênero no trabalho bancário informatizado. Cadernos Pagu (10), p.147-168, 1998.

Silva, Pedro Luís B; Melo, Marcus André. O processo de implementação de políticas públicas no Brasil: características e determinantes da avaliação de programas e projetos. Campinas: Núcleo de Estudos em Políticas Públicas/Unicamp, 2000. v. 48.

Sousa, S. M. Mulheres em movimento. São Luís: EDUFMA/PPGCS, 2007.

Souza, Celina. Estado do campo da pesquisa em políticas públicas no Brasil. Revista Brasileira de Ciências Sociais, São Paulo, v. 18. n. 51, p. 15-20, fev. 2003.

. Estado da arte da pesquisa em políticas públicas. In: Hochman, G; Arretche, M; Marques, E. (Org.). Políticas públicas no Brasil. Rio de Janeiro: Fiocruz, 2007.

Stromquist, Nelly. Políticas Públicas de Estado e equidade de gênero: perspectivas comparativas. Revista Brasileira de Educação, Rio de Janeiro, n. 1, jan./abr. 1996. 


\section{Resumo - Resumen - Abstract}

\section{Pró-equidade de gênero: incorporando políticas de ação afirmativa no mundo do} trabalho

Elisabeth Lisbôa Pinto; Hermes Andrade Júnior e Rodolfo Pinto da Luそ

A instituição do Programa Pró-equidade de Gênero é o reconhecimento público da desigualdade de tratamento e de oportunidades, que ainda permanece entre mulheres e homens. A implementação é consolidada com a colocação em prática dos planos de ações firmados entre a Secretaria Especial de Políticas para as Mulheres (SPM) e as organizações aderentes. A pesquisa exploratória teve como objetivo apresentar o programa e discuti-lo com base no modelo "policy cycle como aprendizado", de Silva e Melo (2000). Os resultados subsidiarão pesquisa futura sobre a avaliação do programa. Dentro da estratégia adotada, a coleta de dados ocorreu em documentos institucionais e dados bibliográficos em março de 2009, com o seguinte resultado: a avaliação não trata de forma clara da efetividade e da sustentabilidade do programa. Este trabalho está dividido em seis partes: descrição do método utilizado; apresentação do Programa Pro-equidade de Gênero; avaliação de suas duas primeiras edições; breve contextualização das políticas públicas no Brasil e o modelo "policy cicle como aprendizado"; relações entre o programa e o modelo; e considerações finais.

Palavras-chave: políticas públicas, gênero, Programa Pró-equidade de Gênero.

En favor de la equidad de género: incorporando políticas de acción afirmativa en el mundo del trabajo

Elisabeth Lisbôa Pinto; Hermes Andrade Júniory Rodolfo Pinto da Luz

La institución del Programa en favor de la Equidad de Género es el reconocimiento público de la desigualdad, del trato y de las oportunidades otorgado a las mujeres. La aplicación esta consolidada con la puesta en práctica de los Planes de Acción firmados entre la Secretaría Especial de Políticas para las mujeres (SPM) y las organizaciones que hacen parte. La investigación tiene como objetivo presentar el programa y discutirlo con base en el modelo "police cycle como aprendizado" de Silva y Melo (2000). Los resultados servirán como ayuda para investigaciones futuras sobre la evaluación del programa. Dentro de la estrategia adoptada la colecta de datos ocurrió en documentos de instituciones y datos bibliográficos en marzo de 2009, con los siguientes resultados: la evaluación no trata de manera clara de la efectividad o de la sustentabilidad del programa. Este trabajo está dividido en seis (6) partes: en la primera es descrito el método utilizado; la segunda presenta el programa en favor de la equidad de género y la evaluación de sus dos primeras ediciones; la tercera y cuarta partes discuten una breve contextualización de las políticas públicas en el Brasil y el modelo "policy cycle como aprendizaje"; siguiente que las relaciones del programa y otras partes del modelo, y las preocupaciones definitivas.

Palabras clave: políticas públicas, género, Programa en favor de la Equidad de Género.

\section{Pro-equity Gender: including affirmative policies in the world of labor Elisabeth Lisbôa Pinto; Hermes Andrade Júnior and Rodolfo Pinto da Luz}

The constitution of the Pro-equity Gender Program shows the public admission of the unequal treatment and opportunities granted to women. This implementation is consolidated with the putting into practice of the Action Plans agreed between the Special Secretariat of Women Policies (SWP) and the organizations members. The survey description has the purpose to present the program and discuss it on the model "policy cycle as a learning", from Silva e Melo (2000). Results 
will give subsidies to future research on the program evaluation. Within the adopted strategy, data were collected on March 2009, through institutional documents and bibliographic data, with the following result: the assessment does not deal with the program effectiveness and sustainability in a clear way. This work is divided in six parts: in the first one is described the used method; then, it is presented the Pro-equity Gender Program and the assessment of its first two editions; the third and fourth part discusse in brief the composition of public policies in Brazil and the model "policy cycle as a learning"; the following parts treat of the relationships among the program and the model, and the final considerations.

Keywords: policy, gender, Pro-equity Gender Program

Elisabeth Lisbôa Pinto

Mestranda do Programa de Mestrado em Administração do Centro Universitário Euro-Americano (Unieuro), Brasília-DF. Contato: bethlisboa@uol.com.br

Hermes Andrade Júnior

Professor do Programa de Mestrado em Administração do Centro Universitário Euro-Americano (Unieuro), Brasília-DF. Contato: handradejunior@gmail.com

Rodolfo Pinto da Luz

Professor do Programa de Mestrado em Administração do Centro Universitário Euro-Americano (Unieuro), Brasília-DF. Contato: rpl.unieuro@gmail.com 


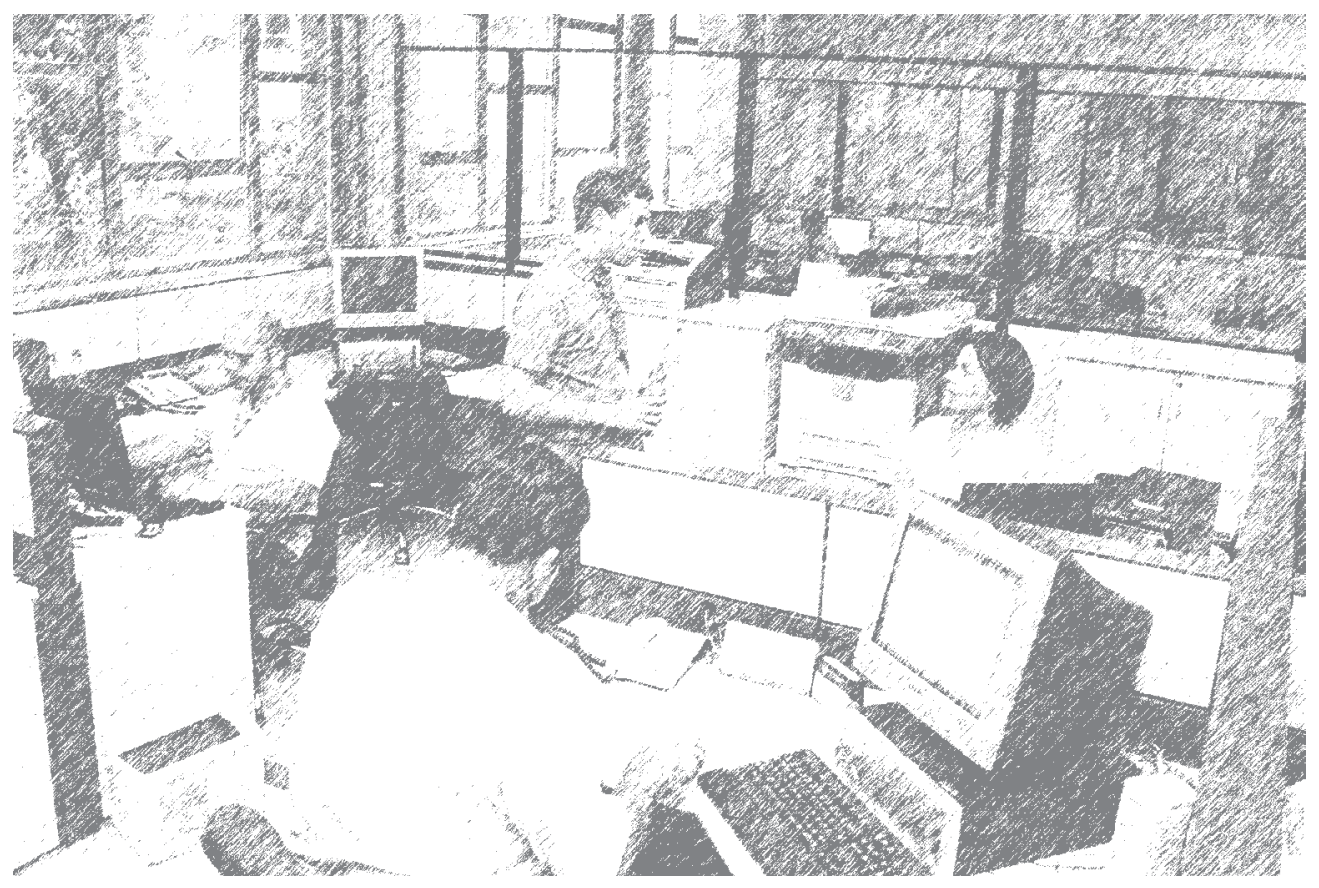

